\title{
Da Mihi Ubi Consistam, Terramque Movebo
}

\section{Antonio Tancredi*}

Unit of General Surgery and Thoracic Surgery, IRCCS Hospital, Italy

This famous saying of Archimedes well describes the need to provide the right tools when you want someone to do something (especially if very important).

In the field of science, and in our specific context of surgery, the most important tool that must be provided to anyone involved in research is open access to knowledge.

In the human history, one of the main problems has always been the limited opportunities for most people to have access to knowledge, infact education has always played a high cost and required to students not to work, then only the richest people have always had the possibility to acculturate. So for many centuries the works of prestige and responsibility, requiring a very good training, like that of the physician and surgeon, were carried out only by people belonging to the wealthier social classes.

A peculiarity of the last century (in the industrialized states), and what we are experiencing, is definitely a low cost school system allowing the poorest people to be able to instruct. In this way the cultural level has risen.

The fact that many people have had the opportunity to devote to knowledge probably caused the increased speed with which science has evolved over the last hundred years than in previous centuries. So the effort to extend the culture at all has been rewarded with a more rapid scientific progress.

From this premise, we understand the importance and innovation of a scientific journal that allows free access.

Open access encourages consultation of the journal, facilitates the dissemination of knowledge and promotes training at no cost and therefore a most rapid evolution of science. What is a scientific discovery if none or only a few can know?

The free access to scientific journals is the future, and certainly it will give a further positive boost to the research and training of new doctors and surgeons.

In a rapidly changing world, also the surgeons must adapt to news, especially a surgeon cannot exist without a research setting, interest in innovation and therefore the research must be part of the mentality of surgeon and this new mindset, more complete, is favoured only if it is free access to innovation. Another important point that must be addressed and solved is the possibility to do research without restrictions and to publish free, so if open access is an achievement of this moment we must not stop, for the future we must aim to promote the free publication. Only the free flow of ideas and findings encourages the comparison, and only by comparing the progress is achieved.
*Corresponding author: Antonio Tancredi, Unit of General Surgery and Thoracic Surgery, IRCCS Hospital, Italy, E-mail: antoniotancredi@virgilio.it

Received August 02, 2011; Accepted August 20, 2011; Published January 19, 2012

Citation: Tancredi A (2012) Da Mihi Ubi Consistam, Terramque Movebo. Surgery 2:e105. doi:10.4172/2161-1076.1000e105

Copyright: (c) 2012 Tancredi A. This is an open-access article distributed unde the terms of the Creative Commons Attribution License, which permits unrestricted use, distribution, and reproduction in any medium, provided the original author and source are credited. 